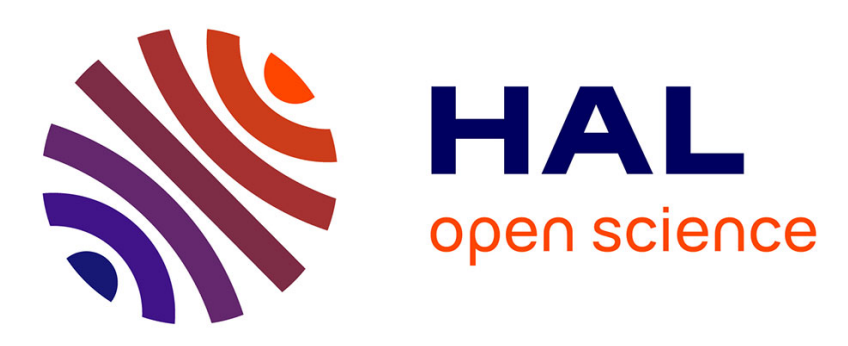

\title{
Picosecond third-order nonlinearity of lead-oxide glasses in the infrared
}

\author{
Cid de Araújo, Edilson Falcao-Filho, A. Humeau, Dominique Guichaoua, \\ Georges Boudebs, Luciana Kassab
}

\section{- To cite this version:}

Cid de Araújo, Edilson Falcao-Filho, A. Humeau, Dominique Guichaoua, Georges Boudebs, et al.. Picosecond third-order nonlinearity of lead-oxide glasses in the infrared. Applied Physics Letters, 2005, 87 (22), pp.221904. 10.1063/1.2137457 . hal-01389338

\section{HAL Id: hal-01389338 \\ https://hal.science/hal-01389338}

Submitted on 8 Oct 2021

HAL is a multi-disciplinary open access archive for the deposit and dissemination of scientific research documents, whether they are published or not. The documents may come from teaching and research institutions in France or abroad, or from public or private research centers.
L'archive ouverte pluridisciplinaire HAL, est destinée au dépôt et à la diffusion de documents scientifiques de niveau recherche, publiés ou non, émanant des établissements d'enseignement et de recherche français ou étrangers, des laboratoires publics ou privés.

\section{(c)(1)}

Distributed under a Creative Commons Attribution| 4.0 International License 


\title{
Picosecond third-order nonlinearity of lead-oxide glasses in the infrared
}

Cid B. de Araújo ${ }^{\text {a) }}$ and E. L. Falcão-Filho

Departamento de Física, Universidade Federal de Pernambuco, 50670-901 Recife, PE, Brazil

\begin{abstract}
A. Humeau, D. Guichaoua, and G. Boudebs
Laboratoire des Propriétés Optiques des Matériaux et Applications, UMR CNRS 6136, Université d'Angers, 2 Boulevard Lavoisier, 49045 Angers Cedex 01, France

Luciana R. P. Kassab

Laboratório de Vidros e Datação, Faculdade de Tecnologia de São Paulo-FATEC, 01124-060 São Paulo, São Paulo, Brazil
\end{abstract}

(Received 12 July 2005; accepted 4 October 2005; published online 22 November 2005)

\begin{abstract}
Heavy metal-oxide glasses containing lead and bismuth were prepared, and their picosecond third-order nonlinear (NL) optical characteristics were investigated. NL refractive indices of $\approx 10^{-18} \mathrm{~m}^{2} / \mathrm{W}$ at $1064 \mathrm{~nm}$ were measured. Negligible NL absorption was verified and, as a consequence, the samples present a good factor-of-merit for photonic applications. (C) 2005 American Institute of Physics. [DOI: 10.1063/1.2137457]
\end{abstract}

Glasses with high nonlinearity have been extensively studied in the past years by many authors (Refs. 1-6, and references therein). Presently it is well known that there is a direct relation between the nonlinear (NL) refractive index, $n_{2}$, of a glass and the polarizability of its constituents. For example, the presence of heavy-metal ions increases $n_{2}$. From the applied point of view transparent NL glasses have many advantages compared to inorganic crystals and organic materials because of their fast response times, small linear losses, and negligible two-photon absorption coefficient, $\alpha_{2}$, for wavelengths in the infrared. In particular the heavy metal-oxide glasses containing lead and bismuth deserve much attention because of their large potential for photonic applications. These glasses have high refractive indices, large transmission window in the visible and near infrared, and cutoff phonon energy varying from $\approx 500$ to $\approx 700 \mathrm{~cm}^{-1}$. They are very stable and resistant to moisture. ${ }^{1-6}$

This work presents measurements of the NL properties of four compositions of lead-oxide glasses at $1064 \mathrm{~nm}$, using the $Z$-scan technique. ${ }^{7}$ Large values of $n_{2}$ and small values of $\alpha_{2}$ were determined, and the results were compared with the Boiling, Glass, and Owyoung (BGO) model. ${ }^{8}$ A good agreement is found between experimental and theoretical values.

The oxide glasses investigated in this work were obtained following the procedure described in Refs. 3-5 starting with the following composition in weight percent: 46 $\mathrm{PbO}-10 \quad \mathrm{Ga}_{2} \mathrm{O}_{3}-42.6 \quad \mathrm{Bi}_{2} \mathrm{O}_{3}-1.4 \quad \mathrm{BaO}$ (sample $\mathrm{A}$ ); $46 \mathrm{PbO}-12 \mathrm{Ga}_{2} \mathrm{O}_{3}-42 \mathrm{Bi}_{2} \mathrm{O}_{3}$ (sample $\mathrm{B}$ ); $13.3 \mathrm{PbO}-55.5$ $\mathrm{GeO}_{2}-31.2 \quad \mathrm{Bi}_{2} \mathrm{O}_{3}$ (sample $\mathrm{C}$ ); and $35.3 \mathrm{PbO}-48.9$ $\mathrm{PbF}_{2}-15.8 \mathrm{~B}_{2} \mathrm{O}_{3}$ (sample $\mathrm{D}$ ). The reagents were melted in platinum (samples A, B, and D) and alumina (sample C) crucibles, at $1000{ }^{\circ} \mathrm{C}$, for $1 \mathrm{~h}$, quenched in air (in a heated brass mold), annealed for $1 \mathrm{~h}$, at $300^{\circ} \mathrm{C}$ (samples A and B, considering the transition temperature of $330{ }^{\circ} \mathrm{C}$ ) and at $420{ }^{\circ} \mathrm{C}$ (samples $\mathrm{C}$; transition temperature $\approx 430{ }^{\circ} \mathrm{C}$ ) and then cooled to room temperature, inside the furnace. Finally,

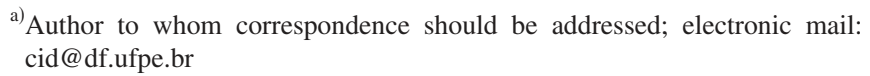

samples with dimensions $10 \times 10 \times 2 \mathrm{~mm}^{3}$ and good optical quality were cut and polished for the experiments.

Optical absorption spectra of the samples were measured with a double beam spectrophotometer from 200 to $2000 \mathrm{~nm}$ and the linear index of refraction was measured at $632.8 \mathrm{~nm}$ and at $1550 \mathrm{~nm}$ using the prism-coupler technique. The results are shown in Figs. 1(a) and 1(b).

NL refraction and NL absorption were investigated using the $Z$-scan technique. ${ }^{7}$ Figure 2 shows the setup used. The excitation is provided by a linearly polarized mode-locked
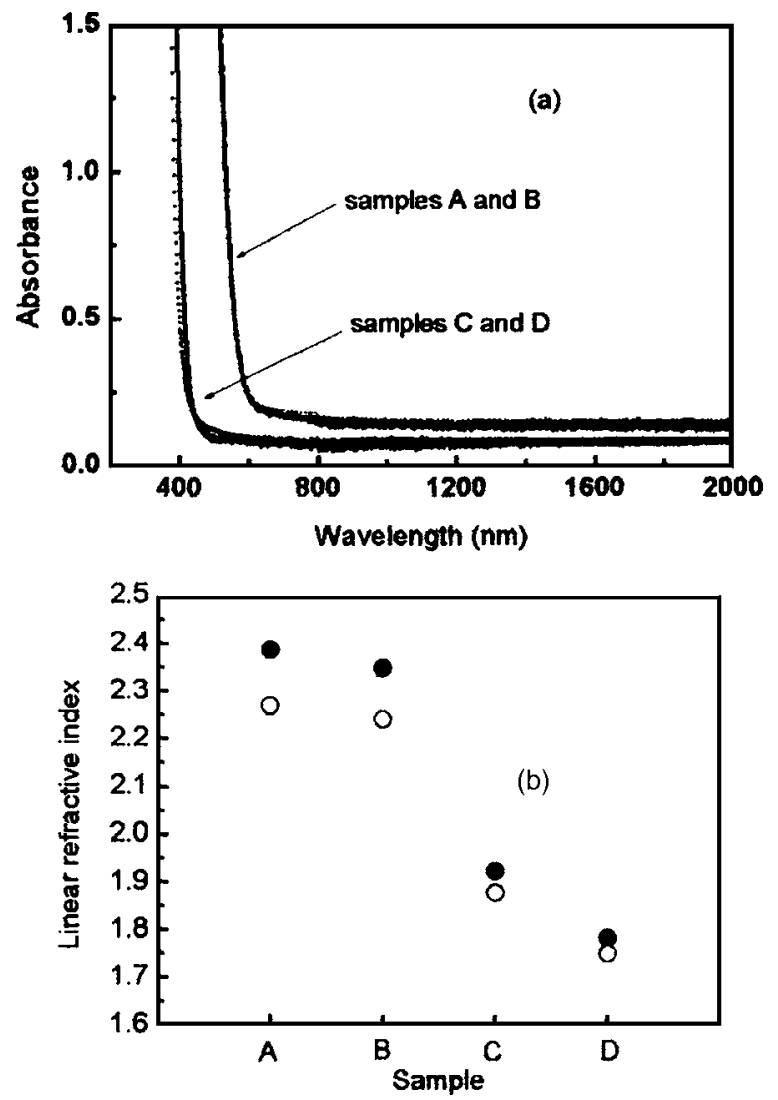

FIG. 1. (a) Absorption spectra. (b) Linear refractive indices. Full dots $(632.8 \mathrm{~nm})$. Open dots $(1550 \mathrm{~nm})$. 


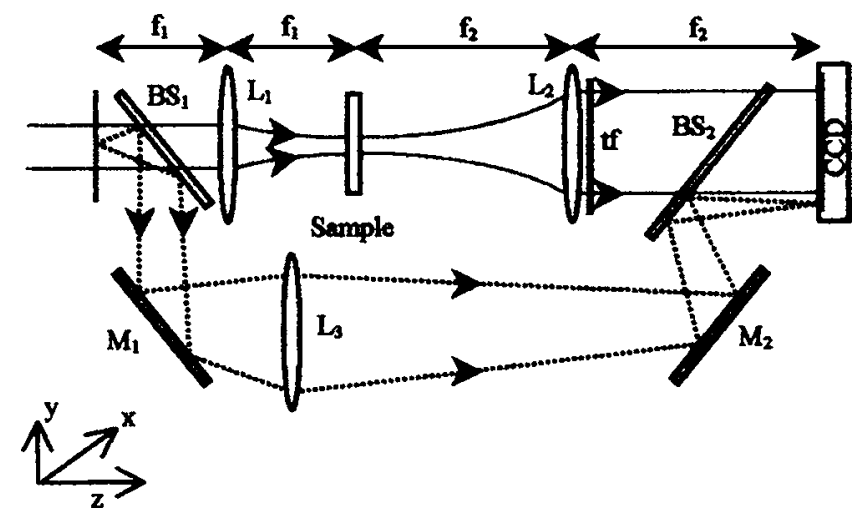

FIG. 2. Schematic of the experimental setup. The sample is located in the focal region. The labels refer to: lenses $\left(L_{1}-L_{3}\right)$; mirrors $\left(M_{1}, M_{2}\right)$; beam splitters $\left(B S_{1}, B S_{2}\right)$; neutral filters $(t f)$.

$\mathrm{Nd}$ :yttrium-aluminum-garnet laser (1064 nm; pulse duration of $15 \mathrm{ps} ; 10 \mathrm{~Hz}$ ). The Gaussian laser beam is focused using lens $L_{1}$ with focal distance $f_{1}=20 \mathrm{~mm}$. The waist radius at the focal plane is $w_{0}=30 \mu \mathrm{m}$, corresponding to a Rayleigh length of $2.7 \mathrm{~mm}$. The measurements were performed using a $4 f$ system with two different incident intensities on the samples $\left(I_{0}=2.1\right.$ and $\left.4.4 \mathrm{GW} / \mathrm{cm}^{2}\right)$. The image receiver is a $1000 \times 1018$ pixels cooled camera $\left(-30^{\circ} \mathrm{C}\right)$ operating with a fixed gain. It is placed at a distance equal to $f_{2}=20 \mathrm{~mm}$ from lens $L_{2}$ in order to obtain the image of the focal plane into the charge coupled device. A reference beam incident in a small area of the camera allows to monitor the energy fluctuation of the laser. The sample is moved in the focus region along the beam propagation direction ( $Z$ axis). Negative values of $Z$ correspond to locations of the sample between the focusing lens and its focal plane. Open and closed $Z$-scan normalized transmittance were numerically processed from the acquired images by integrating over all the pixels in the first case and over a circular numerical filter in the second one (giving a linear aperture transmittance $S$ equal to 0.2). Lens $L_{2}$ contributes to produce the Fourier transform of the field at the exit surface of the sample, which is physically similar to the far field diffraction obtained with the original $Z$-scan method. The simplified Eq. (13) in Ref. 7 relating the nonlinear dephasing to $\Delta T_{\mathrm{pv}}$, the difference between the normalized peak and valley transmittance, remains valid for the $4 f$ system. For more experimental details concerning our $Z$-scan procedure, see Ref. 9, and references therein.

Figure 3 shows $Z$-scan traces for samples A and B measured at $2.1 \mathrm{GW} / \mathrm{cm}^{2}$. The profiles are characteristic of positive nonlinearity. Samples C and D also present positive $n_{2}$. NL absorption was not observed for all samples, which implies that the two-photon absorption coefficients are below the detection limit $\left(\alpha_{2}<0.1 \mathrm{~cm} / \mathrm{GW}\right)$. The magnitude of $n_{2}$ is obtained by comparison with the value for $\mathrm{CS}_{2}, 3$ $\times 10^{-18} \mathrm{~m}^{2} / \mathrm{W}$, that was used as a calibration standard. Table I summarizes the results and gives the mean value of $n_{2}$ obtained at 2.1 and $4.4 \mathrm{GW} / \mathrm{cm}^{2}$.

To evaluate the potential of the present materials for alloptical switching devices, it was calculated the figure-ofmerit (FOM), $n_{2} / \lambda \alpha_{2}$, and the results are in Table I. It can be seen that samples A and B present FOM $>1$ and they are expected to have good performance in all-optical switching applications. ${ }^{10}$

Using the BGO model, ${ }^{8}$ it was possible to estimate values for $n_{2}$ which are in agreement with the experimental
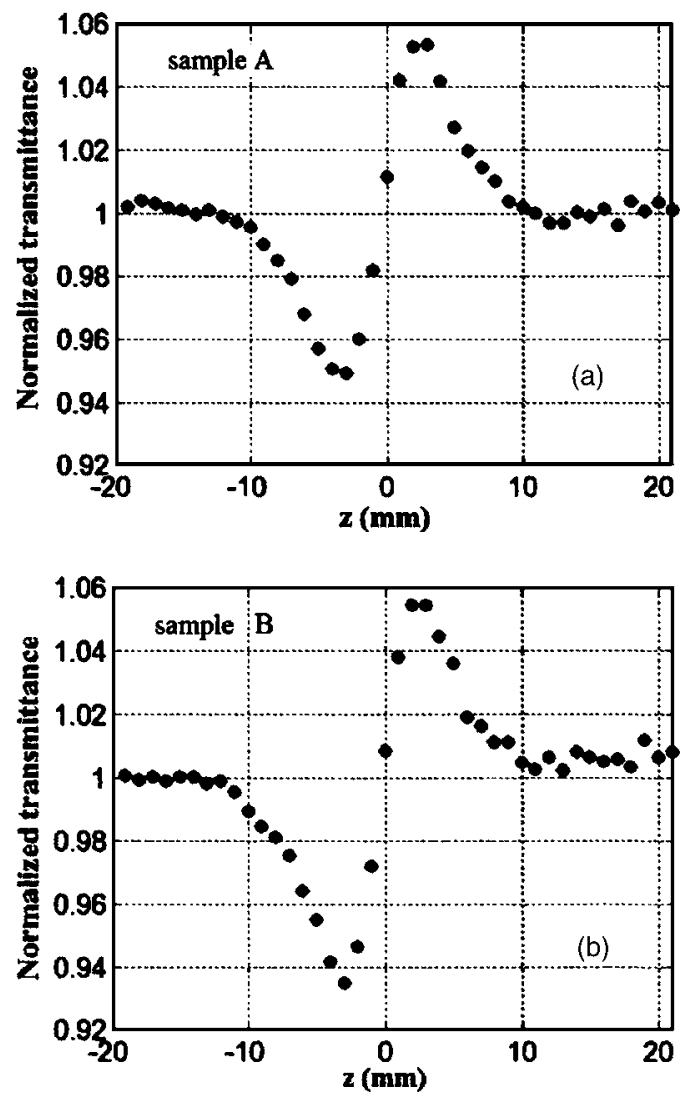

FIG. 3. Experimental $Z$-scan transmittances (points) for sample A $(1.60 \mathrm{~mm}$ thick) and sample $B(2.0 \mathrm{~mm}$ thick $)$ for $I_{0}=2.1 \mathrm{GW} / \mathrm{cm}^{2}$ at $\lambda=1.06 \mu \mathrm{m}$.

data. In the BGO model the NL polarizability is assumed to be proportional to the linear polarizability squared and the optical dispersion of the medium is determined by only one resonance at frequency $\omega_{0}$. The incident light field of frequency $\omega$ is considered to be far from resonance $\left(\omega \ll \omega_{0}\right)$ and $n_{2}$, written in Gaussian units, is given by

$$
n_{2}[\mathrm{esu}]=\frac{\left[n_{0}(\lambda)^{2}+2\right]^{2}\left[n_{0}(\lambda)^{2}-1\right]^{2}}{48 \pi n_{0}(\lambda) \hbar \omega_{0}} \frac{(g s)}{(N s)},
$$

where $N$ is the density of nonlinear oscillators, $s$ is the effective oscillator strength, $g$ is a dimensionless parameter given by $g=\mu s \hbar / m \omega_{0}$, where $\mu$ is the nonlinear coupling coefficient, $(2 \pi \hbar)$ is the Planck's constant, and $m$ is the electron mass. The linear refractive index for light wavelength $\lambda$ is denoted by $n_{0}(\lambda)$ and satisfies the expression

$$
\frac{4 \pi}{3} \frac{\left[n_{0}(\lambda)^{2}+2\right]}{\left[n_{0}(\lambda)^{2}-1\right]}=\frac{\omega_{0}^{2}-\omega^{2}}{\left(e^{2} / m\right)(N s)},
$$

where $e$ is the electron charge in Gaussian units.

TABLE I. Linear refractive index $\left(n_{0}\right)$ at $1064 \mathrm{~nm}$, NL refractive index $\left(n_{2}\right)$, two-photon absorption coefficient $\left(\alpha_{2}\right)$, figure-of-merit $\left(n_{2} / \alpha_{2} \lambda\right)$, and pre-

\begin{tabular}{|c|c|c|c|c|c|c|}
\hline Glass & $n_{0}$ & $\begin{array}{l}\text { Thickness } \\
(\mathrm{mm})\end{array}$ & $\begin{array}{c}n_{2} \\
\left(10^{-18} \mathrm{~m}^{2} / \mathrm{W}\right)\end{array}$ & $\begin{array}{c}\alpha_{2} \\
(\mathrm{~cm} / \mathrm{GW})\end{array}$ & $n_{2} / \alpha_{2} \lambda$ & $\begin{array}{c}n_{2}(\mathrm{BGO}) \\
\left(10^{-18} \mathrm{~m}^{2} / \mathrm{W}\right)\end{array}$ \\
\hline A & 2.3 & 1.60 & 1.6 & $\leqslant 0.1$ & $>1.5$ & 1.4 \\
\hline B & 2.3 & 2.00 & 1.3 & $\leqslant 0.1$ & $>1.2$ & 1.2 \\
\hline $\mathrm{C}$ & 1.9 & 1.05 & 0.4 & $\leqslant 0.1$ & $>0.4$ & 0.33 \\
\hline $\mathrm{D}$ & 1.75 & 3.05 & 0.3 & $\leqslant 0.1$ & $>0.3$ & 0.21 \\
\hline
\end{tabular}
dictions of the BGO model $\left[n_{2}(\mathrm{BGO})\right]$. 
The parameters $N s$ and $\omega_{0}$ are obtained from the values of $n_{0}(\lambda=632.8 \mathrm{~nm})$ and $n_{0}(\lambda=1550 \mathrm{~nm})$ measured for each sample. Then, the values of $N s$ and $\omega_{0}$ are introduced in Eq. (1) to determine $n_{2}$. The value of $g s=3$ was used here since it is an appropriate value for oxides. ${ }^{8,11}$ The value of $n_{0}(\lambda$ $=1064 \mathrm{~nm}$ ), was determined using Eq. (2) with the values of $N s$ and $\omega_{0}$ obtained for each sample. The results calculated for $n_{2}$ at $1064 \mathrm{~nm}$, in units of $10^{-18} \mathrm{~m}^{2} / \mathrm{W}$, are 1.4 (sample A), 1.2 (sample B), 0.33 (sample C), and 0.21 (sample D) which are in agreement with the measured values.

In summary, the NL refraction and NL absorption of heavy metal-oxide glasses were determined for excitation at $1064 \mathrm{~nm}$. Samples with larger concentration of $\mathrm{PbO}$ and $\mathrm{Bi}_{2} \mathrm{O}_{3}$ present larger nonlinear refractive indices. The results indicate large potential of the samples for photonic applications.

C.B.deA. acknowledges the Université d'Angers for financial support during his stay at P.O.M.A. Financial support by the Brazilian agencies Conselho Nacional de Desenvolvimento Científico e Tecnológico (CNPq), Fundação de Amparo à Ciência e Tecnologia do Estado de Pernambuco
(FACEPE), and Fundação de Amparo à Pesquisa do Estado de São Paulo (FAPESP) is also acknowledged.

\footnotetext{
${ }^{1}$ See for instance, M. Yamane and Y. Asahara, Glasses for Photonics (Cambridge University Press, Cambridge, 2000).

${ }^{2}$ J. H. Song, J. Heo, and S. H. Park, J. Appl. Phys. 93, 9441 (2003).

${ }^{3}$ L. R. P. Kassab, M. E. Fukumoto, and L. Gomes, J. Opt. Soc. Am. B 22, 1255 (2005), and references therein.

${ }^{4}$ L. R. P. Kassab, L. C. Courrol, R. Seragioli, N. U. Wetter, S. H. Tatumi, and L. Gomes, J. Non-Cryst. Solids 348, 94 (2004).

${ }^{5}$ L. R. P. Kassab, L. C. Courrol, V. D. D. Cacho, S. H. Batumi, N. U. Wetter, L. Gomes, and N. I. Morimoto, J. Non-Cryst. Solids 348, 103 (2004).

${ }^{6}$ S. Smolorz, I. Kang, F. Wise, B. G. Aitken, and N. F. Borrelli, J. NonCryst. Solids 256\&257, 310 (1999).

${ }^{7}$ M. Sheik-Bahae, A. A. Said, T. Wei, D. J. Hagan, and E. W. van Stryland, IEEE J. Quantum Electron. 26, 760 (1990).

${ }^{8}$ N. L. Boiling, A. J. Glass, and A. Owyoung, IEEE J. Quantum Electron. QE-14, 601 (1978).

${ }^{9}$ G. Boudebs and S. Cherukulappurath, Opt. Commun. 250, 416 (2005).

${ }^{10}$ G. Stegeman, in Nonliner Optics of Organic Molecules and Polymers, edited by H. S. Nalva and S. Miyata (CRC Press, Boca Raton, FL, 1997), p. 799.

${ }^{11}$ R. Adair, L. L. Chase, and S. A. Payne, Phys. Rev. B 39, 3337 (1989).
} 